Plano ENENORTE, Plano 95, Conjunto de Projetos Especiais da ELETROBRÁS, 1979, Plano 2000. Plano de Expansão Correspondente ao Programa de Recuperação Financeira do Setor Elétrico 1985

2. Documentos de Planejamento do GCPS Grupo Coordenador de Planejamento do Sistema Elétrico, especialmente o Boletim de Planejamento.

3. Metodologia de Planejamento do Sistema Elétrico - Trabalho apresentado ao SPISE-BRACIER 1985 - José Luiz AIqueres e outros.

4. Planejamento do Setor Elétrico - Conjun to de artigos apresentados nos Boletins de 1984 e 1985 da ABCE - Associação Brasileira de Concessionárias de Energia Elétrica e de autoria de António Carlos Tatit Holtz.

\title{
A administração unificada das empresas de energia do Estado de São Paulo
}

\section{JOSÉ GOLDEMBERG}

Reitor da Universidade de Sảo Paulo. Bacharel em Ciências pela USP e pos-graduado pela Universidade de Saskatcewan, Canadá. Foi presidente da CESP, CPFL, ELETROPAULO e COMGÁS.

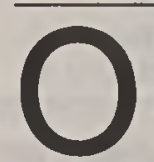

Governo do Estado de São Paulo detém o controle acionário de quatro empresas de energia. Destas, três são de energia elétrica: a CESP - Companhia Energética de São Paulo; a CPFL - Companhia Paulista de Força e Luze a ELETROPAULO - Ele tricidade de São Paulo S/A. - e uma de gás, a COMGAS Companhia de Gás de São Paulo. Esta última passou ao controle da CESP em novembro de 1984. Até então, era uma empresa do munićpio de São Paulo.

Além dessas três empresas de energia elétrica, atuam ainda em São Paulo dez outras, de pequeno porte, pertencentes à iniciativa privada. No entanto, cabem àquelas a responsabilidade pelo atendimento de $95 \%$ dos consumidores paulistas, que, por sua vez, consomem $97 \%$ da energia elétrica utilizada no Estado de São Paulo, conforme mostra a tabela.

Ainda com a intençẩo de mostrar ó tamanho e a importância das empresas de energia elétrica do Governo do Esta. do de São Paulo, gostaríamos de comparar a potência instalada e a produção da CESP lempresa geradora, supridora e fornecedoral com os valores do Brasil como um todo.

Em 1984, a capacidade geradora ins. talada da CESP, toda ela hidráulica, era de $8.468 \mathrm{MW}$ (outros 4.031 MW estavam em construçãol, valor que representava, na ocasiāo, perto de $24 \%$ da potência de geração hidráulica instalada no Brasil lou $20 \%$ do total brasileiro, quando se considera em conjunto a hidráulica mais a térmica).

Naquele ano, a produção da CESP totalizou 43,3 TWh (43,3 bilhöes de KWh), valor que representou cerca de $25 \%$ de toda energia elétrica produzida no Brasil.

Desde março de 1983, as empresas de energia elétrica passaram a ter Administração Unificada, ou seja, um só Presidente e um só Conselho de Administra- ção para todas elas. Hoje, entre elas está incluída a COMGÁS.

Por que uma Administração Unificada? Por que não uma Secretaria de Estado? Por que não uma empresa "holding", nos moldes da ELETROBRÁS? ou, ainda, por que não fusioná-las? Estas e muitas ou tras interrogaçōes foram colocadas às equipes que, neste campo, assessoravam o candidato eleito para governar São Paulo. Todas as possibilidades foram es estudadas com o máximo de cuidado.

A proposta escolhida foi a da Administração Unificada e com ela pôde o Governo assegurar unidade de comando a todo o complexo energético do Estado, concedendo, inclusive, o status de Secretário de Estado ao Presidente das empresas. Com isso, as trés empresas passaram a trabalhar de maneira integrada, inclusive no que diz respeito à otimização dos recursos disponíveis, man. tidas as características próprias de cada uma e sempre visando ao objetivo comum e prioritário que é atender, o mais eficazmente possivel, aos interesses do povo paulista.

A manutençāo das características próprias de cada uma das empresas tornou-se extremamente importante, pois na forma de agir, a experiência vem sendo acumulada, como no caso da CPFL e da ELETROPAULO, por perfodo superior a sete décadas.

Logo no in ício do Governo Montoro, foi criado o Conselho Estadual de Energia, integrado por representantes do Governo, do empresariado, das Universidades e dos trabalhadores, com a função precipua de traçar a política energética global no Estado de São Paulo.

\section{Os problemas iniciais}

De infcio, a Administração Unificada encontrou uma série de dificuldades decorrentes da conjuntura adversa que atingia toda a economia brasileira: uma forte recessão unida a uma alta taxa de inflação, que infelizmente ainda permanece; um endividamento externo, cujo montante atingia indices insustentáve is e, ainda, a reduçāo da atividade indus trial, que trouxe ao setor elétrico, em particular para as empresas de São Pau. lo, conseqüências de duas ordens: a que. da acentuada das taxas de crescimento 
QUADRO 1

\section{CESP/CPFL/ELETROPAULO}

ÁREAS DE CONCESSÃO

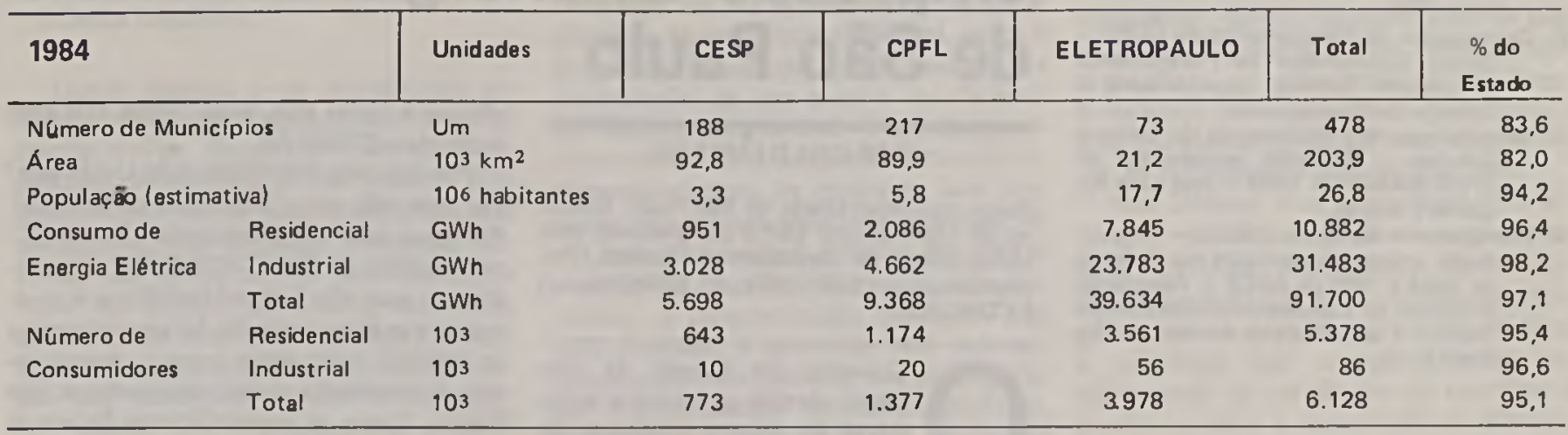

do consumo industrial (que responde por mais de $50 \%$ do consumo total) e, por ou trolado, altos indices de desemprego, principalmente na Grande São Paulo (região atendida pela ELETROPAULO) que, por sua vez, trouxeram como conseqüência aumentos consideráveis de inadimplèncias no consumo residencial.

$\checkmark$ ale a pena fazer um parêntese a respeito do problema dos inadimplentes. $A$ legislação permite que a empresa corte o fornecimento de energia elétrica a todo consumidor que deixar de pagar sua conta de luz. Se isto fosse feito, teriam sido agravados, sobremaneira, os problemas sociais gerados pelo desemprego. Isto não ocorreu graças à iniciativa do Governo paulista em permitir atrasos no pagamento da conta de luz (de água tam bém), de até seis meses ao consumidor de até $60 \mathrm{kWh}$, que estivesse desempregacio.

Gostarfamos ainda de citar outro grande problema que até hoje atinge o setor elétrico como um todo: trata-se do problema tarifário, cujos indices fixados de forma irreal colaboram para que a taxa de remuneração média do setor fique muitos pontos abaixo da taxa legal (10 a $12 \%$ do investimento remunerável).

Aliado a todos esses problemas, podemos citar ainda a difícil situação econômico-financeira herdada pela atual Administração, tais como: uma divida externa (da CESP), no valor de US\$ 2,2 bilhões e ainda um grande montante de compromissos vencidos e não pagos, fazendo com que as empresas, para a continuidade de seus serviços, fosem obrigadas a fazer captações crescentes, tanto para a rolagem das dívidas como para que pudessem ser mantidos os indices programados de investimento (caso da CESP e da ELETROPAULO).
Além disso, recebemos também como herança os compromissos firmados com os fornecedores de bens e serviços para um programa de obras que compreende quatro usinas e o canal de $\mathrm{Pe}$ reira Barreto, que liga o Rio Tietê ao Lago de Ilha Solteira, programa este incompativel com a época de recessão a que já nos referimos. Incompativel também com os balanços energéticos, de médio prazo, projetados para o Estado de São Paulo.

\section{Enlace Empresarial}

Relacionamos a seguir algumas medidas tomadas para viabilizar o início da Administração Unificada.

Uma das primeiras, adotada antes mesmo da posse da atual administração, foi o trabalho realizado com respeito aos Estatutos Sociais das três empresas, visando proporcionar respaldo jurídicoinstitucional e condiçōes operacionais à Administração Unificada.

Outra medida, esta com a Administração já em pleno exercicio, foi a celebração, em caráter particular, de um "Contrạto Básico de Colaboração" entre as três empresas: CESP, CPFL e ELE. TROPAULO, com o obje tivo de:

“... regular a colaboração mútua entre as partes, visando a otimização no uso de seus recursos humanos e materiais, sempre que necessário, em regime de comunidade de trabalho,..."

Tendo por base esse Contrato, em termos práticos, inúmeras ações foram desencadeadas, logo após a sua assinatura, através de "pactos adjetos" específicos.

Uma delas, por exemplo, é a possibilidade de utilização conjunta, pelas três empresas, dos escritórios da ELETRO. PAULO, no Rio de Janeiro e em Brasília. lo, no Rio de Janeiro e em Brasília.

Outra ação trata dos serviços na área de transportes, possibilitando a utilização, de forma comum e integrada, dos serviços de manutenção da frota, abastecimento e transporte de pessoal e de carga.

A propaganda institucional das empresas foi centralizada e sua ação ficou vinculada a objetivos comuns definidos pela Administração Unificada. Do mesmo modo, foi criada uma marca dando a imagem visual dessa forma de Administração: Energia de São Paulo - Administração Unificada, incluindo nomes, a princípio, das três empresas, e hoje das quatro, pois foi acrescentado o da COMGÁS.

A instituição da Agência para Aplicacão de Energia foi outra das medidas tomadas nos primeiros meses da atual gestão. Assim, "com a finalidade de desenvolver e coordenar programas voltados à aplicação de energia no Estado de São Paulo, incentivando a utilização de fontes energéticas nacionais, com ênfase especial à energia elétrica, promovendo a substituição de combustiveis importados e a conservação de energia, estimu. lando o aumento da participação da energia elétrica no consumo de energia e harmonizando a atuação das Concessionárias de Energia do Estado, a CESP. CPFL e ELETROPAULO, de comum acordo, e com base na decisāo do Conselho de Administração adotada na reunião de 20 de maio de 1983, resolvem ampliar os objetivos e competências da Agência pa. ra Aplicação de Eletricidade e instituir a Agência para Aplicação de Energia.

Entre os instrumentos criados para viabilizar a Administração Unificada, incentivando também maior participação 
do corpo gerencial das empresas, foi institu ído pela Presidéncia o "Programa de Enlace Empresarial", atualmente o principal programa de ação administrativa. Implementado desde o início da atual Administração, visa obter, a nivel das três empresas de energia elétrica:

- ação empresarial integrada;

- uniformização de políticas, diretrizes e critérios; e

- racionalização na utilização dos recursos.

O Programa de Enlance vem abrangendo gradativamente a totalidade das áreas de Gestão Empresarial. Seu caráter participativo se revela na medida que, atuando a nivel gerencial, formamse "Grupos de Enlance" espesíficos sob a coordenação geral da Presidência.

Embora o forum seja o Grupo de Enlace, obtém-se contribuição de empregados de todos os niveis hierárquicos envolvidos.

Assim, a solução dos problemas levantados sai de quem tem dele maior vivência $e$, freqüentemente, a solução não é nenhuma das adotadas individualmente nas empresas, mas uma outra, inédita e criativa, que responde à necessidade das empresas, evitando o ônus da estrutura burocrática resultante de eventual fusão.

As dificuldades encontradas para o desenvolvimento dos vários grupos de enlace - como resistências iniciais internas, diversidade de critérios e procedimentos, processo decisório próprio e mesmo questões de ordem jurídico-tributárias - revelaram aspectos interessantes da diferenciada cultura empresarial cristalizada na CESP, CPFL e ELETROPAULO.

Em diferentes fases de atuação, os Grupos de Enlace instituidos e atualmente em funcionamento, são os seguintes:

Recursos Humanos, Informática,

Transporte, Suprimentos, Comunica-

ção, Desenvolvimento Organizacio-

nal, Jurídico, Finảnceiro, Comercial,

Engenharia de Distribuição e Inspeção de Materiais e Equipamentos.

Para todos os grupos, a metodologia de trabalho adotada prevé as seguintes etapas:

- identificação de pontos de interesses e pontos críticos; ções;

análise e equacionamento das solu-

- proposição à aprovação da Presi. dencia, ouvida a Diretoria específica, de medidas comuns para adoção pelas empresas;
- acompanhamento e avaliaçäo das medidas adotadas.

Instituído de forma a servir como ferramenta auxiliar para viabilização de uma administração unificada, o Progra. ma de Enlace Empresarial trouxe outros benefícios entre seus subprodutos, como uma gradativa mudança de mentalidade e de comportamento gerencial no âmbito das empresas, criando as condições essenciais para um trabalho cooperativo e de integração.

A título de exemplo, relacionamos os resultados mais significativos de alguns dos Grupos de Enlace.

\section{Recursos Humanos}

- Unificação das políticas de Recursos Humanos envolvendo acordos coletivos, administração de salários, beneficios, estágios, etc.

- Acompanhamento conjunto e de. senvolvimento de negociações em condições semelhantes para os acordos coletivos junto aos sindicatos.

- Equiparação de escala de salários para chefias e de nivel hierárquico equivalente nas 3 empresas, pesquisa salarial conjunta, uniformização de beneficios previdenciários e médicos (Fundaçảo CESP).

- Em fase adiantada os estudos para implantação de um Plano de Carreira que atenda não só à necessidade das empresas como à antiga aspiração dos em. pregados.

\section{Informática}

Intercâmbio permanente de informaçōes e sistemas comıpativeis, uso comum de equipamentos e materiais e atendimento mútuo das áreas de informática em situação de emergéncia.

\section{Transportes}

- Integração operacional, pela utilização conjunta de recursos de serviços, oficinas de manutenção e postos de abastecimento.

- Modelo único de administração de transporte e normatização do "pool de transporte".

- Em estudo à compatibilização de critérios para fixação da taxa de reembolso por quilometragem pela utilização do veículo próprio do empregado, quando a serviço.

\section{Comunicação}

- Adequação das estruturas organiza. cionais das áreas de comunicação das empresas.

- Centralização das atividades de pro- paganda institucional na Presidência, como desdobramento da criação da marca "Energia de São Paulo - CESP/CPFL/ ELETROPAULO".

- Criação da revista "São Paulo Ener. gia", abrangendo as atividades neste campo nas 3 empresas, cuja direção editorial está centralizada na Presidência Unificada.

\section{Suprimentos}

- Aproveitamento integrado de materiais disponíveis em estoque.

- Padronização e simplificação dos procedimentos de cadastramento de fornecedores.

- Unificação do Regulamento de Licitações para as 3 empresas.

- Utilização de um modelo único de Banco de Preços.

Inspeção de Materiais de Equipamentos

- Colaboração mútua na área de inspeção de materiais e equipamentos.

- Uniformização de critérios e proce. dimentos de inspeção.

- Troca de experiéncia entre as em. presas.

\section{Jur ídico}

- Apoio jurídico às atividades dos demais grupos de enlace, sobretudo no aspecto institucional, fiscal e tributário.

- Análise jurídica dos diversos "Pactos adjetos" ao contrato básico de colaboração firmado entre as empresas.

- Encaminhamento consensado de questões das três empresas junto aos governos Estaduais e Federal.

- Formalização do Regulamento de Licitações único entre as empresas.

\section{Financeiro}

- Análise financeira das açōes resul. tantes de colaboração entre as empresas, como pactos, rateios de despesas, compensações, etc.

- Fixação de valores comuns para diárias de viagem ao exterior e estudos para uniformização de diárias de viagem no País.

- Suporte contábil e fiscal aos diversos Grupos de Enlace.

- Uniformização de critérios na colaboração e apresentação de orçamento.

\section{Comercial}

- Compatibilização e uniformização de critérios e procedimentos comerciais das 3 empresas.

- Criação de programas comuns especiais de atendimento a consumidores. 
- Participação e organização conjunta das empresas em eventos que exijam participação das áreas comerciais.

- Aplicação uniforme da legislação especifica nas empresas.

- Uniformização de critérios para atendimento à população de baixa renda.

- Tarifas especiais para consumidores individuais (EGTD, EFST, ETST).

- Políticas comuns da recuperação de débitos, de eletrificação rural e de concessão de donativos.

Obs.: Este grupo conta com a participacão da Agência para Aplicação de Energia, órgão da Presidência Uni. fica.

\section{Engenharia de Distribuição}

Uniformização de padrões e especificações técnicas, visando o fornecimento de energia a consumidores individuais de baixa tensão e para edificios de uso coletivo, nas 3 empresas.

\section{Políticas comuns ds empresas de energia}

A Administração Unificada das empresas de energia estabeleceu, entre os objetivos do Programa de Enlace, a uniformização de políticas, diretrizes e critérios.

Do elenco de políticas administrativas implantadas na atual gestão, algumas das quais específicas em cada uma das empresas, foram envidados esforços no sentido de se chegar a políticas comuns, entre elas as de Recursos Humanos (reenquadramento funcional, promoçōes, plano de carreira, mérito, recrutamento) Estudos Organizacionais, Patrimônio Imobiliário, Contratação de mãode-obra e Desapropriaçōes

\section{Conclusão}

A Administração Unificada das empresas de energia do Governo do Estado de São Paulo acumulou, ao longo desses dois anos, exatamente a metade do seu mandato, uma série de experiências. Numerosas dificuldades foram ou estão sendo superadas, uma vez que nas empresas as diferenças - tais como: diversidade de critérios e de procedimentos; processo decisório; questões de ordem contábil, jurídica, fiscal e tributária eram (e ainda sảo, em certo nivel) muito acentuadas, agravadas que foram, em tempos anteriores, pela natural disputa entre empresas.

Assim, ao completarmos o segundo ano de Administração Unificada, podemos dizer que o primeiro - 1983 foi marcado pela reorganização das empresas no sentido de ter um Conselho de Administração e uma Presidência unificados, consolidando e dando maior coordenação às suas atividades. $E$, o segundo ano - 1984 - ficou marcado como o ano em que as empresas, apesar da crise que afetou o setor, conseguiram ampliar a capacidade de atendimento e consolidar a postura de Companhias a serviço da comunidade.

\section{FIGURA 1}

Administraçōo Unificada

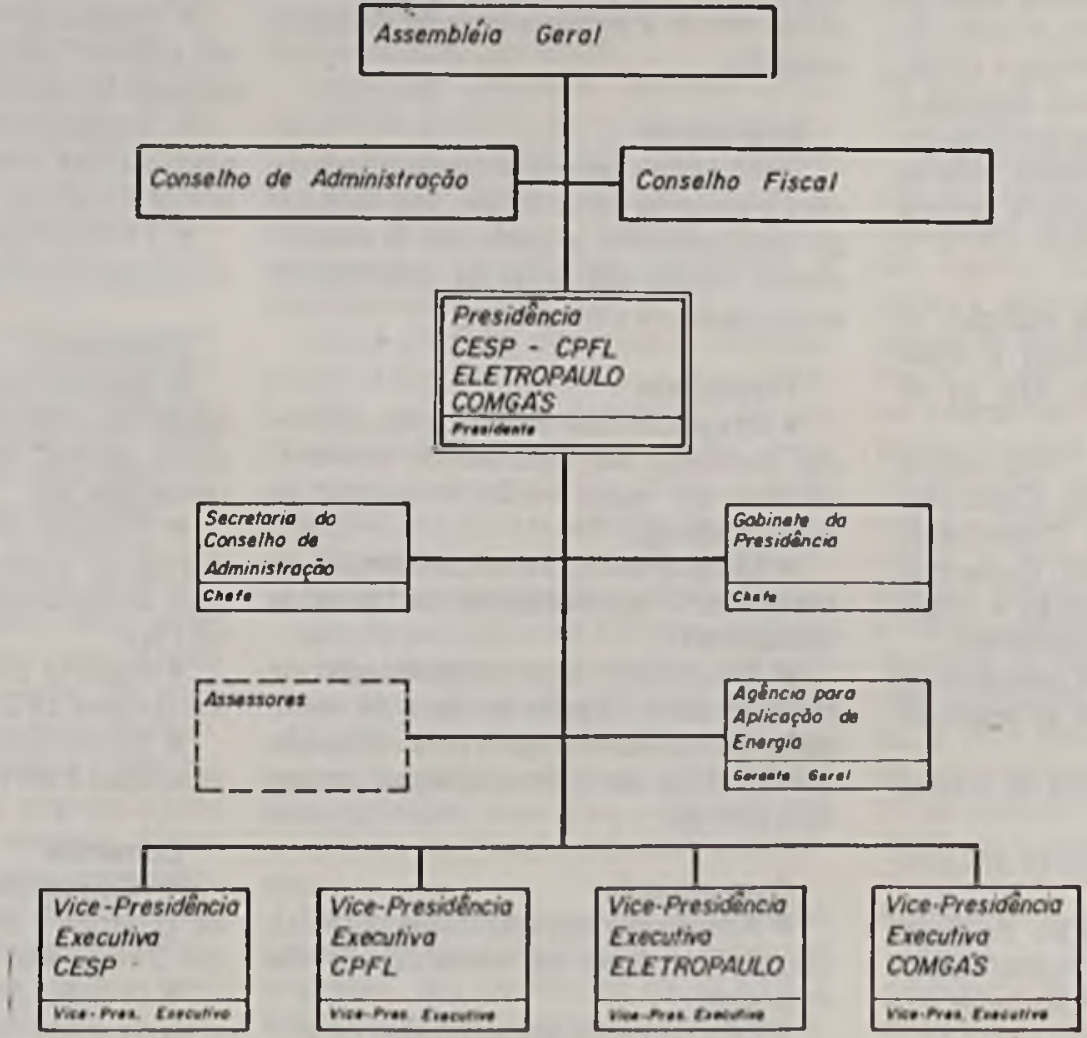

